pulmonary circulation and a varying obstruction of pulmonary perfusion, thus resulting in clinically unspecific symptoms of dyspnea, cough, or impaired right ventricular function mimicking pulmonary thromboembolism in the majority of cases. ${ }^{2-4}$

The radiologic diagnosis can still be difficult despite the technologic advances in imaging techniques. ${ }^{1,5}$ Preoperative biopsy is the only way to establish a proper diagnosis, and it is essential to accurately plan the surgical approach. ${ }^{5}$

The only treatment of choice is radical surgical resection. ${ }^{4}$ Depending on tumor localization and distal extension, surgical treatment includes PA resection, a polytetrafluoroethylene (Gore-Tex) homograft, or even xenograft reconstruction and pneumonectomy. The use of cardiopulmonary bypass may be essential in patients in whom the tumor originates from the PA trunk or the pulmonary valve. As a palliative treatment, endovascular stent grafting may be an alternative therapeutic option in inoperable cases. Furthermore, neoadjuvant or adjuvant chemotherapy has been mentioned in the literature with doubtful results.

Prolonged tumor-free survival is rare. A 10-month survival is reported in the literature for different sarcomas of $\mathrm{PA},{ }^{5}$ whereas in our series survival was 7 and 2.5 years, respectively.

\section{Conclusion}

Early diagnosis along with aggressive and extensive surgical treatment in patients with PA leiomyosarcoma without any extrathoracic metastases may provide an opportunity for prolonged survival in addition to palliation.

\section{References}

1. Dumont P, Diot P, Aupart MR, Toumieux B. Leiomyosarcoma of the pulmonary artery. Ann Thorac Surg. 1998;66:2089-91.

2. Mengel M, Fraund S, Haverich A, Kreipe HH. Primary leiomyosarcoma of the pulmonary artery - a case report. Pneumologie. 2000; 54:20-3.

3. Mazzucco A, Luciani GB, Bertolini P, Faggian G, Morando G, Ghimenton C. Primary leiomyosarcoma of the pulmonary artery: diagnostic and surgical implications. Ann Thorac Surg. 1994;57:222-5.

4. Choong CK, Lawton JS, Moon MR, Damiano RJ Jr. Failure of medical therapy for pulmonary "thromboembolic" disease: beware the unsuspected primary sarcoma of the pulmonary artery. $J$ Thorac Cardiovasc Surg. 2004;128:763-5.

5. Hoffmeier A, Semik M, Fallenberg EM, Scheld HH. Leiomyosarcoma of the pulmonary artery-a diagnostic chameleon. Eur J Cardiothorac Surg. 2001;20:1049-51.

\title{
A new approach to the assessment of aortic cusp geometry
}

\author{
Hans-Joachim Schäfers, MD, PhD, Benjamin Bierbach, MD, and Diana Aicher, MD, Homburg/Saar, Germany
}

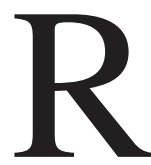

epair of the aortic valve is a new surgical approach to the treatment of aortic regurgitation. Regurgitation of the aortic valve can be caused by cusp distortion, root dilatation, or a combination of both. For good functional reconstruction, all pathologic components present have to be addressed. Good results have been achieved with valve-preserving aortic replacement, ${ }^{1}$ but isolated aortic valve reconstruction (ie, cusp repair for prolapse) still remains a challenge to surgical judgment.

The main problem in repair of aortic cusps is assessment of pathology and the repair result. Root dilatation can easily be quantified preoperatively by means of echocardiography or intraoperative measurements. Cusp geometry, however, is difficult to quantify by means of echocardiography. Measurements of cusp

From the Department of Thoracic and Cardiovascular Surgery, University Hospitals of Saarland, Homburg/Saar, Germany.

Received for publication March 29, 2006; accepted for publication April 5, 2006.

Address for reprints: Hans-Joachim Schäfers, MD, PhD, Department of Thoracic and Cardiovascular Surgery, University Hospitals of Saarland, 66421 Homburg/Saar, Germany (E-mail: h-j.schaefers@uniklinikum-saarland.de).

J Thorac Cardiovasc Surg 2006;132:436-8

$0022-5223 / \$ 32.00$

Copyright $\odot 2006$ by The American Association for Thoracic Surgery doi:10.1016/j.jtcvs.2006.04.032 dimensions are difficult to standardize intraoperatively, and these dimensions determine cusp configuration only in conjunction with sinus dimensions. ${ }^{2}$

The typical configuration of a normal aortic valve is not only characterized by root dimensions but also the configuration of the cusps. This includes a typical height difference between the central free margins and the aortic insertion lines (Figure 1, A). ${ }^{3}$ We have designed a caliper that allows easy and reproducible measurement of this height difference, which we call effective height as opposed to 2-dimensional cusp height. ${ }^{2}$ This measurement allows for identification of prolapse in the native cusps and assessment of prolapse correction after valve repair.

\section{Technical Description}

After cardioplegia, stay sutures are placed in the aortic commissures and kept under tension in the exact direction of the commissures (as seen from the center of the root). The caliper is placed such that the longer end rests on the lowest (ie, central) point of the insertion line. The shorter end is pushed to the free margin, with the curve accommodating the margin (Figure 1,B). The height difference of the cusp (free edge to insertion) can be measured in millimeters.

In normal aortic valves we have found effective height to range from 8 to 10 millimeters, which correlated $\pm 1 \mathrm{~mm}$ with intraoperative transesophageal measurements. In approximately 50 repair operations, we have found good correlation between effective 

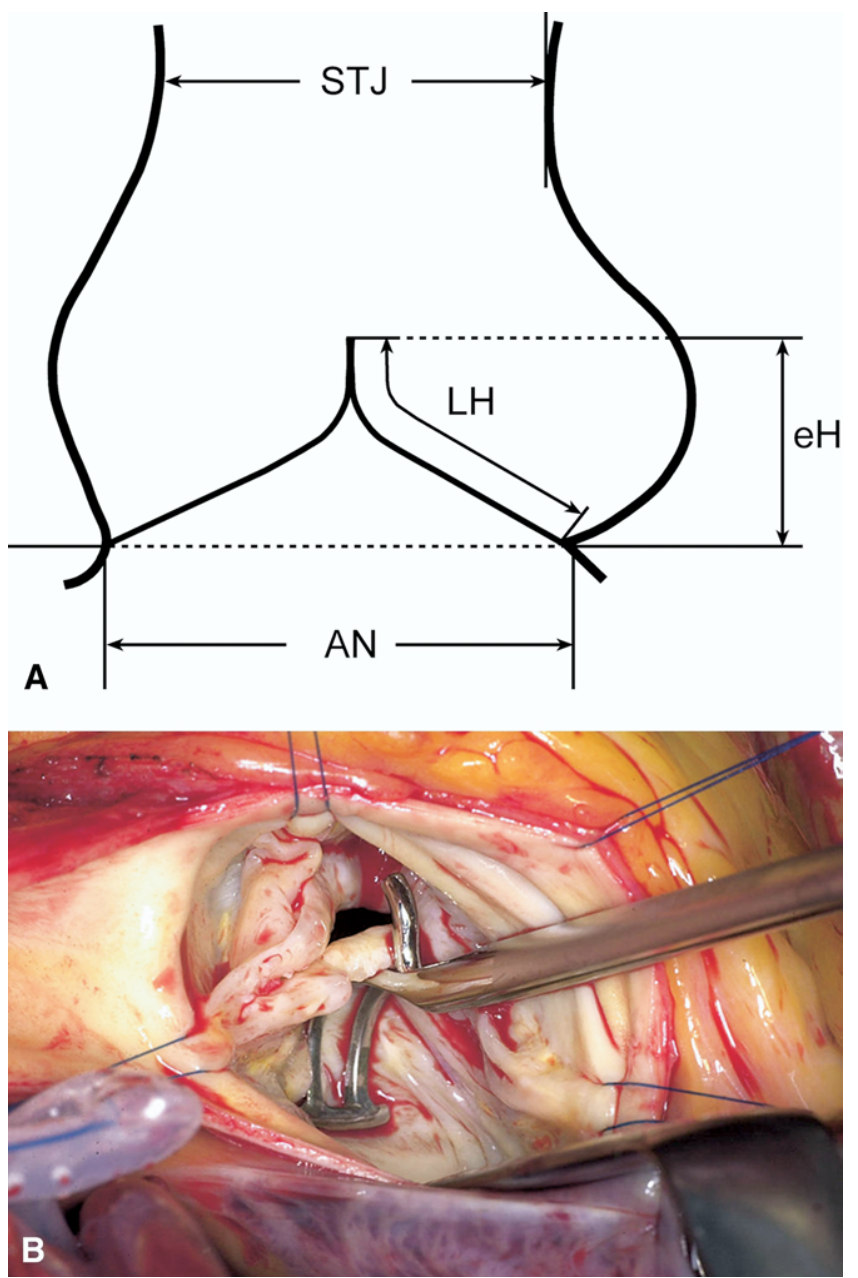

Figure 1. A, Schematic drawing of the aortic valve and root. Effective height is the height difference between the central free margins and the aortic insertion lines. This can be measured intraoperatively with a caliper. STJ, Sinutubular junction; $A N$, annulus or aortoventricular junction; $L H$, leaflet or cusp height; $e H$, effective height. B, Intraoperative photograph showing measurement of the effective height of the noncoronary cusp of a bicuspid aortic valve with the caliper. The caliper is placed such that the longer end rests on the lowest (ie, central) point of the insertion line. The shorter end is pushed to the free margin, with the curve accommodating the margin.

height measured intraoperatively and by means of postoperative echocardiography. Cusp prolapse found on preoperative echocardiography (Figure 2, A) was confirmed by means of intraoperative measurement. Cusp and valve configuration were normalized by shortening of the free margins to a height difference of $8 \mathrm{~mm}$, with corresponding echocardiographic measurements (Figure 2, B).

\section{Discussion}

Aortic cusp geometry has been defined by sinus dimensions, length of cusp insertion, cusp height, and length of free margin (ie, denominators that determine the 3-dimensional configuration as a prerequisite for normal valve function). Sinus dimensions can be determined by means of echocardiography, but cusp dimensions cannot be determined preoperatively. Even intraoperative measurement of parameters like cusp height, length of insertion line, or free margin is difficult. Most importantly, these parameters are only interdependent determinants of valve configuration, and their single relevance is limited.

Cusp prolapse can be an isolated pathology of the aortic valve and is often confined to one cusp both in bicuspid and tricuspid aortic valve anatomy. Prolapse can also coexist with root dilatation, and it might be induced by reduction of root diameters, particularly at the sinutubular level. Prolapse of one cusp can be recognized by comparing the relative length of the free margins. Prolapse of 2 or 3 cusps is much more difficult to assess because the reference points (the other cusp margins) are also abnormal. This is important in generalized prolapse, which can occur in the native valve ${ }^{4}$ or as a consequence of valve-preserving surgery. ${ }^{5}$ After reconstructive surgery, these valves function with acceptable regurgitation initially, but failure within the first years after repair has not been infrequent.

We have made the observation that repaired valves with low effective height between the free margin and aortic insertion progressed in regurgitation and required reoperation. In patients with aortic regurgitation, effective height has been as low as $4 \mathrm{~mm}$ (Figure 2, A). We have used an effective height of $8 \mathrm{~mm}$ or more as a goal in the past 50 aortic valve repairs and have been able to achieve good configuration and no regurgitation greater than grade I.

In conclusion, we propose to take effective cusp height into consideration in aortic valve repair and valve-preserving surgery. It can be measured intraoperatively and is a useful guide to quantify cusp prolapse and assess the results of valve-preserving surgery.

\section{References}

1. David TE, Ivanov J, Armstrong S, Feindel CM, Webb GD. Aortic valve-sparing operations in patients with aneurysms of the aortic root or ascending aorta. Ann Thorac Surg. 2002;74(suppl):S1758-61; discussion S1792-9.

2. Kunzelman KS, Grande KJ, David TE, Cochran RP, Verrier ED. Aortic root and valve relationships. Impact on surgical repair. J Thorac Cardiovasc Surg. 1994;107:162-70.

3. Swansson WM, Clark RE. Dimensions and geometric relationships of human aortic valve as a function of pressure. Circ Res. 1974;35:871-82.

4. Shapiro M, Thwaites B, Westgate C, Donaldson R. Prevalence and clinical significance of aortic valve prolapse. Br Heart J. 1985;54: $179-83$.

5. Pethig K, Milz A, Hagl C, Harringer W, Haverich A. Aortic valve reimplantation in ascending aortic aneurysm: risk factors for early valve failure. Ann Thorac Surg. 2002;73:29-33. 

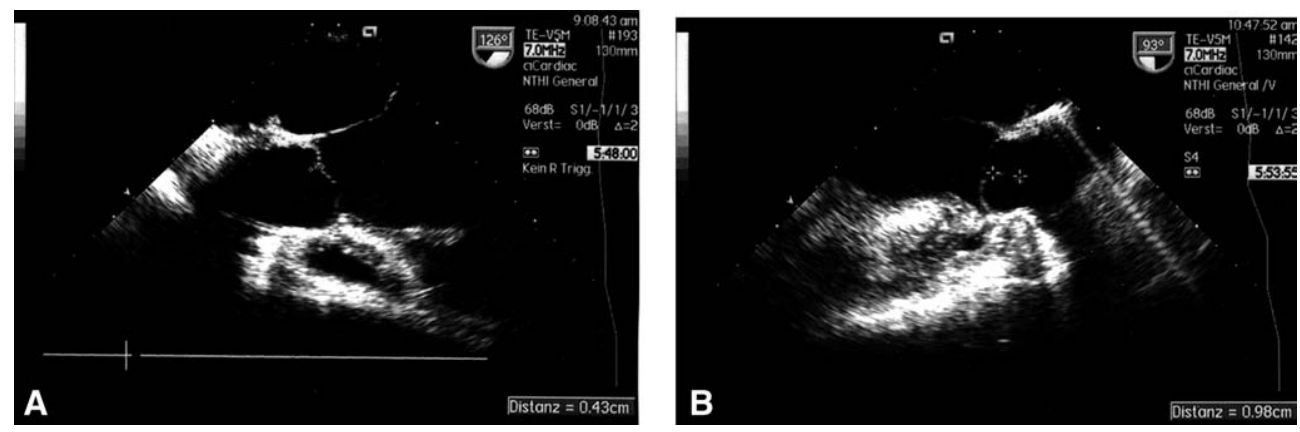

Figure 2. A, Preoperative transesophageal echocardiogram of a patient who presented with grade III aortic regurgitation after valve reimplantation in a different institution. There is some prolapse of the fused cusp and an effective height of $4 \mathrm{~mm}$. Both findings were confirmed by intraoperative measurements. B, Postoperative transesophageal echocardiogram of the same patient after shortening of both cusps. The valve is competent, and an effective height of $10 \mathrm{~mm}$ has been achieved.

\title{
Endovascular treatment of concomitant patent ductus arteriosus and type $B$ aortic dissection in a patient with pulmonary artery dissection
}

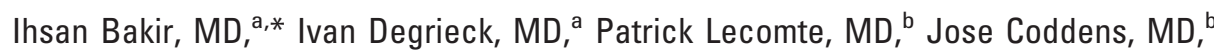
Luc Foubert MD, PhD, ${ }^{\text {b }}$ Alex Heyse, MD, ${ }^{c}$ and Hugo Vanermen, MD, ${ }^{a}$ Aalst, Belgium

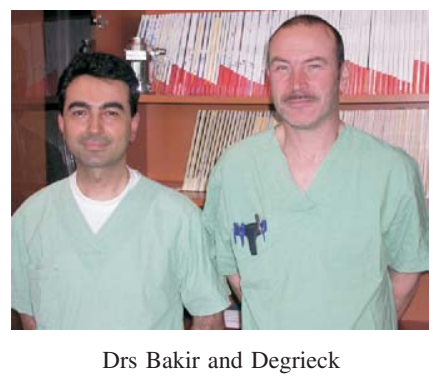

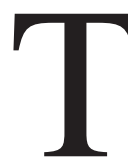

he ideal management of patent ductus arteriosus (PDA) in the older patent is still controversial. Increasing evidence in the literature ${ }^{1,2}$ indicates that transcatheter closure of PDA in this age group is safe and effective. A case of a patient with symptomatic PDA accompanying a chronic type B aortic dissection and silent pulmonary artery (PA) dissection is described.

\section{Clinical Summary}

A 74-year-old woman was admitted with diffuse peripheral edema and orthopnea. Physical examination revealed a continuous murmur on the precordial region. Assessment with transesophageal echocar-

From the Departments of Thoracic and Cardiovascular Surgery ${ }^{\mathrm{a}}$ and Anesthesiology and Critical Care Medicine, ${ }^{\mathrm{b}}$ OLV Clinic, Aalst, Belgium, and the Department of Cardiology, AZ ZVB, ${ }^{\mathrm{c}}$ Ronse, Belgium.

*Dr. Bakir is affiliated with the Department of Cardiovascular Surgery, Siyami Ersek Cardiovascular and Thoracic Surgery Center, Haydarpasa, Istanbul, Turkey. Received for publication Feb 21, 2006; accepted for publication April 10, 2006.

Address for reprints: Ihsan Bakir, MD, OLV Clinic, Cardiovascular and Thoracic Surgery Department, Moorselbaan 164, 9300 Aalst, Belgium (E-mail: ihsanbak@yahoo.com).

J Thorac Cardiovasc Surg 2006;132:438-40

$0022-5223 / \$ 32.00$

Copyright (C) 2006 by The American Association for Thoracic Surgery doi:10.1016/j.jtcvs.2006.04.013 diography revealed an ascending aortic aneurysm of $4.6 \mathrm{~cm}$, dilated right ventricle, dissection of the descending aorta, and an open ductus Botalli. Pulmonary hypertension was estimated from pressure measurements. Computed tomographic (CT) scan confirmed the diagnosis of PDA (diameter $10 \mathrm{~mm}$ ) and type B aortic dissection (Figure 1, $A$ and $B$ ). CT scan also demonstrated a dissection in the truncus pulmonalis (Figure 1, $B$ and $C$ ). It was shown that the flow in the PDA originated from the false lumen of the dissected descending aorta (Figure 1, A) and terminated in the dissected main PA (Figure $1, B$ and $C$ ).

To reduce the risks associated with surgery and age-related comorbidities, the decision was made to close the PDA and concomitantly treat the type B aortic dissection with a stent-graft. With the patient under general anesthesia, the right femoral artery was surgically isolated and a $22 \mathrm{~F}$ introducer sheath was inserted thorough the right femoral artery. An endovascular stent-graft (Gore TAG $40 \mathrm{~mm}$; W. L. Gore \& Associates, Inc, Newark, Del) was inserted into the descending thoracic aorta under fluoroscopic guidance. Aortography confirmed that the stent-graft was properly positioned and that both the origin of the aortic dissection and the PDA were adequately closed (Figure 2, $A$ and $B$ ). The postoperative course was uneventful, and the patient's dyspnea and peripheral edema were diminished after the procedure. A CT scan after 1 week demonstrated satisfactory graft position, without endoleak, and complete closure of the PDA. At 3-month follow-up there were no clinical signs of heart failure: no dyspnea, no peripheral edema, and no pleural effusions. The continuous systolic-diastolic murmur of PDA was no longer observed. 